\title{
A 5G graphene antenna produced by screen printing method
}

\author{
Siti Nor Hafizah Sa'don' ${ }^{1}$ Mohd Haizal Jamaluddin², Muhammad Ramlee Kamarudin ${ }^{3}$, \\ Fauzan Ahmad ${ }^{4}$, Samsul Haimi Dahlan ${ }^{5}$ \\ ${ }^{1,2}$ Wireless Communication Centre, Universiti Teknologi Malaysia, Malaysia \\ ${ }^{3}$ Centre for Electronic Warfare Information and Cyber, Cranfield Defence and Security, Cranfield Univerisity, \\ Defence Academy of the United Kingdom, United Kingdom \\ ${ }^{4}$ Department of Electronic Systems Engineering, Malaysia-Japan International Institute of Technology, \\ Universiti Teknologi Malaysia, Kuala Lumpur \\ ${ }^{5}$ Research Center for Applied Electromagnetic, Faculty of Electrical and Electronic Engineering, \\ Universiti Tun Hussein Onn Malaysia, Malaysia
}

\section{Article Info}

Article history:

Received Sep 3, 2018

Revised Jan 10, 2019

Accepted Feb 25, 2019

\section{Keywords:}

$5 \mathrm{G}$ antenna

Graphene

Graphene antenna

Graphene ink

Screen printing

\begin{abstract}
The save and fast manufacturing are required in order to achieve 5G technology. However, there are many kinds of manufacturing antenna which are depending on material applied in the antenna itself. Each type of manufacturing also has its own advantages and drawback. In this article, a graphene antenna for $5 \mathrm{G}$ applications is manufactured using screen printing method. A fine mesh resolution of $120 \mu \mathrm{m}$ is used to print the antenna accurately. This kind of printing has capability to produce antenna in less than 5 minutes. The antenna made by conductive graphene ink has size of $11.8 \times 12.2 \times 0.076 \mathrm{~mm}^{3}$ and produced within a small amount of graphene ink. The measured antenna resonates at $15.04 \mathrm{GHz}$ with reflection coefficient magnitude of $-12.05 \mathrm{~dB}$ and percentage of impedance bandwidth is $30 \%$ which is in the range of 13.3 to $18.0 \mathrm{GHz}$. The radiation pattern at E-plane and H-plane of the graphene antenna are simulated and measured where the result obtained are comparable.
\end{abstract}

Copyright () 2019 Institute of Advanced Engineering and Science. All rights reserved.

\section{Corresponding Author:}

Mohd Haizal bin Jamaluddin,

Wireless Communication Centre,

Universiti Teknologi Malaysia,

81310 Johor Bahru, Johor, Malaysia.

Email: haizal@fke.utm.my

\section{INTRODUCTION}

In the rapid of wireless communication technology development towards fifth generation (5G), the number of mobile data volume per area and number of connection devices increase more than ten times as well as the increasing of user data rate [1]. This phenomenon directly affecting the growing of cost pressure, efficiency and scalability due to the traffic volume explosion [1, 2]. Accordingly, the improvement in the antenna design has been presented in the manufacturing and material embedded [3-6], mechanism configured [7-9], and network setted up in order to maintain or minimize the cost and energy, and improve the performance of new generation technology so that $5 \mathrm{G}$ criteria is achieved.

In the manufacturing of antenna design, printing technology is one of the recent fabrication method that implemented where conductive ink is printed on substrate in a form of antenna pattern through a printer machine or printing equipment. Several methods have been reported are three-dimentional (3-D) printing [3], [10-12], but the material required that available in market has very low conductivity. While inkjet printing $[13,14]$ is too expensive to be purchased even though in [3] and [13] state that the printing is low-cost, however the method only limited on flexible substrate and can not be used on flat substrate. According to these limitations, screen printing method is the most suitable for $5 \mathrm{G}$ antenna manufacturing 
because another additional technique for conductivity enhancement after printing can be executed [15-17], able to utilize all kind of substrates [18-20] either flexible or flat, the equipment required is very low-cost [21, 22], producing high-resolution patterning [23] and fast. Screen printing is a mass-printing method realized by pressing an ink through a patterned stencil with a squeegee [23]. It has been widely employed for electronics and compatible with a wide variety of functional inks and substrates [23]. Furthermore, it can be used in fine patterning with less than $60 \mu \mathrm{m}$ of multilayer interconnection in integrated circuit but not suitable for thin film which less than $100 \mu \mathrm{m}$ thickness.

In this article, a 5G graphene antenna is fabricated using screen printing method. A conductive graphene ink is printed onto a Kapton polyimide film substrate in antenna design pattern. A screen with mesh resolution of $120 \mu \mathrm{m}$ is used to print the antenna pattern for obtaining the precise printing result. The antenna was designed, optimized and simulated in computer software technology (CST) Microwave Studio. While measurement on reflection coefficient magnitude was done in wireless communication cente (WCC) anechoic chamber, Universiti Teknologi Malaysia and radiation patterned was completed in electromagnetic compatibility (EMC), Universiti Tun Hussein Onn Malaysia. Further detail of this article is, in section 2 presents the antenna design with its specifications and the screen printing process. Then in section 3 , the results and discussion cover the antenna characteristics such as reflection coefficient magnitude, bandwidth, radiation pattern, and gain. Finally, section 4 draws the conclusion.

\section{ANTENNA DESIGN AND SCREEN PRINTING METHOD}

The dimension of graphene antenna is shown in Figure 1(a) and the fabricated graphene antenna is presented in Figure 1(b). It is design in co-planar waveguide (CPW) because of its simplicity and easy-tofabricate during screen printing where the radiator or receiver element and the ground plane are printed on the same surface [24]. The CPW antenna design is selected because of the structure has low dispersion, the ability to control their characteristic impedance and their ease integration with active devices [2] thus suitable in the microwave integrated circuit (MIC) and monolithic microwave integrated circuit (MMIC) applications [26]. The patch antenna dimension is estimated by:

$$
W=\frac{c}{2 f_{o} \sqrt{\frac{\varepsilon_{r}+1}{2}}}
$$

where $c$ is velocity of light, $3 \times 10^{8} \mathrm{~m} / \mathrm{s}, f_{o}$ is frequency and $\varepsilon_{r}$ is dielectric constant. While the CPW transmission line is calculated by $[26,27]$

$$
W_{C P W}=2 G+W_{S}
$$

where $G$ is gap width and $W_{S}$ is transmission line width to obtain $50 \Omega$ characteristic impedance.

However, all the antenna dimensions are optimized while simulating on Computer Software Technlogy (CST) Microwave Studio. The optimizaed antenna size is 11.8 x $12.2 \times 0.076 \mathrm{~mm}^{3}$. A rectangular slot with chamfer is designed to reduce the total antenna size. Formerly, the slot between radiating patch and ground is $0.5 \mathrm{~mm}$, gap width is $0.08 \mathrm{~mm}$, and transmission line width is $4.66 \mathrm{~mm}$, respectively. The antenna is operating at $15 \mathrm{GHz}$. In addition, the screen printed antenna is made by conductive graphene ink where the sheet resistivity is 0.003 to $0.008 \Omega . \mathrm{cm}$ and film thickness is more than $0.1 \mu \mathrm{m}$. The substrate used is Kapton polyimide film with dielectric constant of 3.5 at $1 \mathrm{kHz}$, loss tangent of 0.002 , and $0.075 \mathrm{~mm}$ thick, respectively.

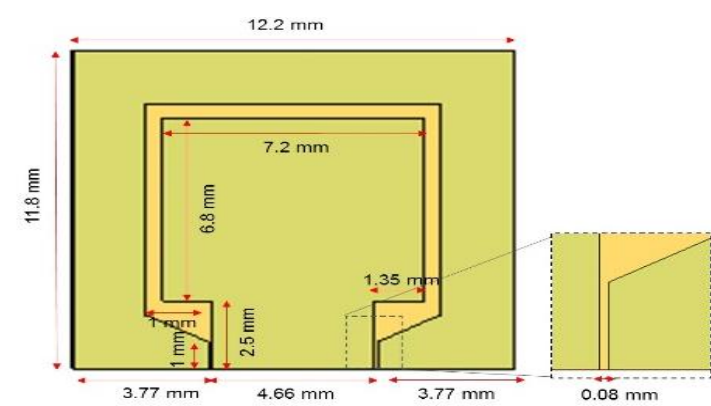

(a)

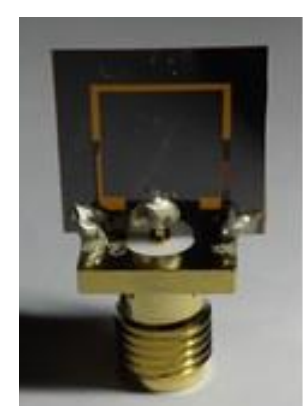

(b)

Figure 1. (a) The parameter length of the antenna design, (b) The screen printed antenna 
The antenna design was sent to a manufacturer in a softcopy file to produce stencil, a wooden frame that containing of antenna pattern as shown in Figure 2(a). The frame was made by fabric and its resolution is $120 \mu \mathrm{m}$. Screen printing is conducted by placing Kapton substrate at the bottom of stencil with a spacer between stencil and substrate. The spacer thickness can be in range of $2 \mathrm{~mm}$ to $3 \mathrm{~mm}$ to avoid the substrate attach to the stencil while printing. The arrangement before screen printing is perfomed has been shown in Figure 2(a). Initially, the graphene ink is pasted on top of stencil near to the antenna pattern by using disposable dropper as shown in Figure 2(b). Then, the ink is spread through antenna pattern by forcing the squeegee rubber and pressing the stencil simultaneously as shown in Figure 2(c). Lastly in Figure 2(d), it shows the pattern result after screen printing. The printing process can be completed in less than 5 minutes excluding curing process on the graphene ink. However, this process can reach up to 45 minutes including curing process on the graphene ink since it is cured for 20 minutes to 30 minutes between $250^{\circ} \mathrm{C}$ to $350^{\circ} \mathrm{C}$. The cost of this printing is spent about RM 3000 including conductive graphene ink, substrate and printing equipments. The graphene ink purchased was bottled in quantity of $10 \mathrm{ml}$ and it is lasting for more than one hundred times for single antenna fabrication. Hence, this fabrication is save. Since the curing temperature and curing time of the graphene ink are in certain range, the measurement result may vary and not exactly the same with the simulation as shown in resonance frequency, bandwidth which are in tolerance of 1 to $2 \mathrm{GHz}$ as well as radiation pattern and gain obtained.

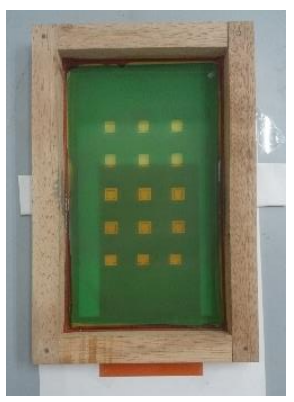

(a)

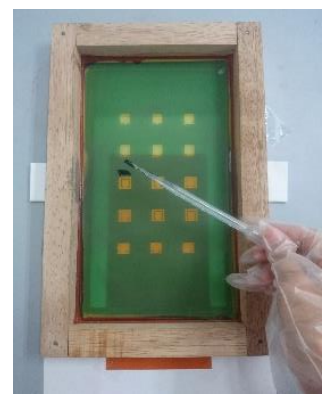

(b)

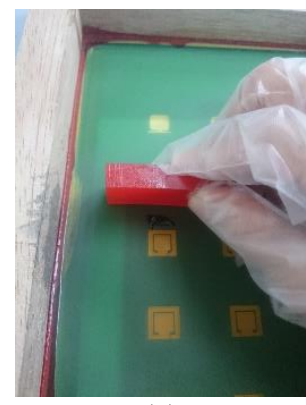

(c)

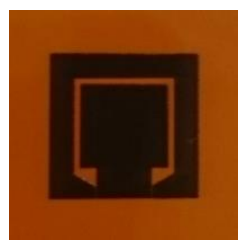

(d)

Figure 2. (a) The arrangement of equipments while screen printing, (b) The deposited ink on stencil, (c) The best incline position of squeegee rubber is at $45^{\circ}$, (d) The graphene ink was printed on Kapton polyimide film substrate

\section{RESULTS AND ANALYSIS}

The operating frequency is designated at $15 \mathrm{GHz}$ as a result of the available equipments which mostly have lower than $18 \mathrm{GHz}$. The reflection coefficient magnitude is simulated using CST Microwave Studio and measured on vector network analyser (VNA) in anechoic chamber of Wireless Communication Centre, Universiti Teknologi Malaysia. Both results are shown in Figure 3. The measured results show that the frequency of $5 \mathrm{G}$ graphene antenna using screen printing resonates at $15.04 \mathrm{GHz}$ with bandwidth of 4.7 $\mathrm{GHz}$ in the interval between $13.3 \mathrm{GHz}$ to $18.0 \mathrm{GHz}$ at $-10 \mathrm{~dB}$ level or $30 \%$. The measured bandwidth is larger than simulation which is $1.47 \mathrm{GHz}$ in the between of $14.25 \mathrm{GHz}$ to $15.72 \mathrm{GHz}$ or $9.8 \%$. The measurement result of resonance frequency is comparable in [27] which is using ferrite but it has narrow bandwidth whereas in [25] is using copper and has the same percentage of impedance bandwidth.

The radiation pattern is measured at Electromagnetic Compatibility (EMC), Universiti Tun Hussein Onn Malaysia. With the purpose of study the radiation pattern at E-plane and H-plane, the comparison results between simulation and measurement are shown in Figure 4 (a) and (b), respectievely. It can be observed that the radiation pattern at E-plane has bidirectional while H-plane is omnidirectional. Two minor lobes appear at E-plane are caused by the presence of other element near to the antenna while measuring. The element is used to hold the antenna from dropping while rotating as the antenna is disconnected from SMA connector before measurement. From the results, the gain obtained for simulation and measurement are $2.39 \mathrm{dBi}$ and $5.86 \mathrm{dBi}$, respectively. The measured gain is extremely lower than simulation because of the graphene is not well conductive while curing stage. The binder contained in the graphene ink may not fully decompose thus avoiding the conductive transformation to be form uniformly. In addition, the range of the curing temperature and curing time given by the supplier is not sufficient thus affected low gain and broader bandwidth. 


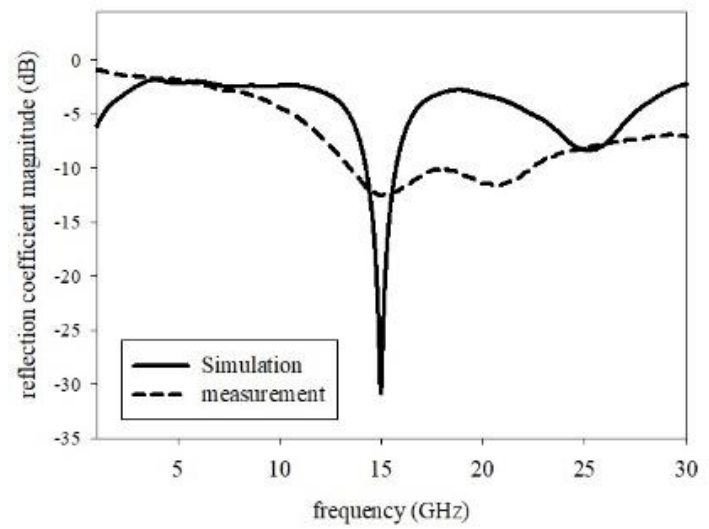

Figure 3. Simulation and measurement of reflection coefficient magnitude

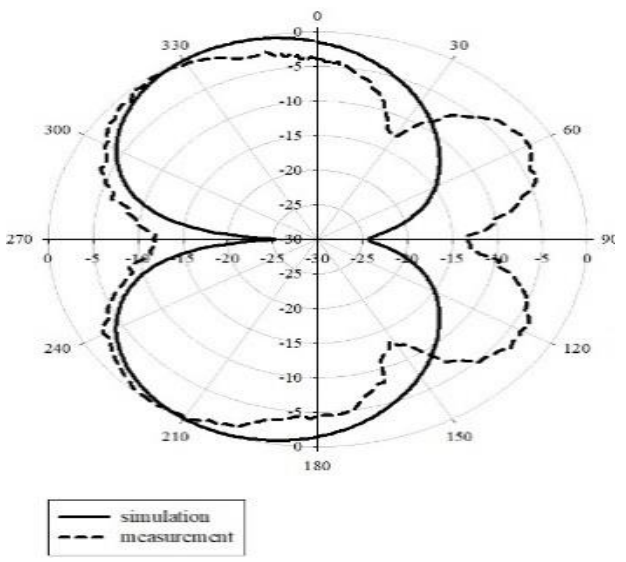

(a)

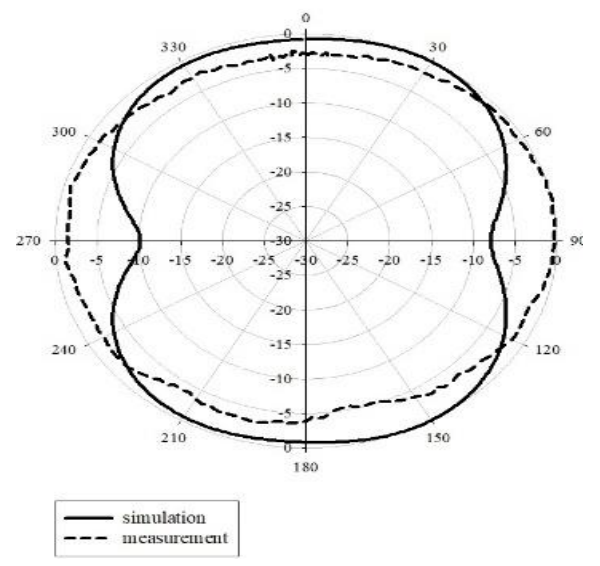

(b)

Figure 4. Simulation and measurement of radiation pattern at (a) E-plane and (b) H-plane.

\section{CONCLUSION}

A graphene antenna is successfully fabricated through screen printing method in this article. The antenna is designed for $5 \mathrm{G}$ application mobile devices. The measured bandwidth antenna is quite wide with $30 \%$. Radiation pattern of the antenna is simulated and measured. Then the comparison of both results are comparable. The curing stage after printing is the challenging process due to the uncontrol effect of temperature onto the graphene conductivity where it also directly affect the antenna result. Thus, it requires a further study on producing higher conductive graphene ink when use binder in order to obtain a better quality of graphene ink in the achieving of $5 \mathrm{G}$ criteria. In the future of $5 \mathrm{G}$ applications, a higher graphene conductive and curing in room temperature can be applied. The antenna then can be used for $5 \mathrm{G}$ antenna array applied in mobile devices. From this research, screen printing method is an alternative way to manufacture $5 \mathrm{G}$ antenna fastly in very low cost.

\section{ACKNOWLEDGEMENTS}

The authors would like to thank the Ministry of Higher Education (MOHE) under FRGS (vote 4F283 and 4F733), Research University Grant (votes 19H56 and 03G59), Higher Centre of Excellence Grant (vote 4J220) and Sciencefund Grant (vote 4S134) for supporting this research work.

\section{REFERENCES}

[1] M. H. Dahri, et al., "A Review of Wideband Reflectarray Antennas for 5G Communication Systems," IEEE Access, vol. 5, pp. 17803-17815, 2017.

[2] A. Osseiran et al., "Scenarios for $5 \mathrm{G}$ mobile and wireless communications: The vision of the METIS project," 
IEEE Commun. Mag., vol. 52, pp. 26-35, 2014.

[3] Y. Li, et al., "A 5G MIMO Antenna Manufactured by 3-D Printing Method," IEEE Antennas Wirel. Propag. Lett., vol. 16, pp. 657-660, 2017.

[4] K. N. Paracha, et al., "Low-Cost Printed Flexible Antenna by Using an Office Printer for Conformal Applications," Int. J. Antennas Propag., vol. 2018, pp. 1-7, 2018.

[5] M. Vural, et al., "Nanostructured flexible magneto-dielectrics for radio frequency applications," J. Mater. Chem. C, vol. 2, pp. 756-763, 2014.

[6] S. N. H. Sa'don, et al., "Graphene array antenna for 5G applications," Appl. Phys. A Mater. Sci. Process., 2017.

[7] J. Ala-Laurinaho, et al., "2-D Beam-Steerable Integrated Lens Antenna System for 5G E-Band Access and Backhaul," IEEE Trans. Microw. Theory Tech., vol. 64, pp. 2244-2255, 2016.

[8] M. Li, et al., "Multiple Antennas for Future 4G / 5G Smartphone Applications," vol. 1, pp. 5-7, 2016.

[9] N. Ojaroudiparchin, et al., "A Switchable 3-D-Coverage-Phased Array Antenna Package for 5G Mobile Terminals," IEEE Antennas Wirel. Propag. Lett., vol. 15, pp. 1747-1750, 2016.

[10] H. He, et al., "3D-Printed Graphene Antennas and Interconnections for Textile RFID Tags: Fabrication and Reliability towards Humidity," Int. J. Antennas Propag., vol. 2017, 2017.

[11] S. Corey, et al., "Multi-layer archimedean spiral antenna fabricated using polymer extrusion 3D printing," Microw. Opt. Technol. Lett., vol. 58, pp. 1662-1666, Apr 2016.

[12] R. Wu, "Integrated printing stereo antenna with dual materials 3D printing technology," Electron. Lett., vol. 54, pp. $118-120$, Feb 2018.

[13] H. Subbaraman, et al., "Inkjet-Printed Two-Dimensional Phased-Array Antenna on a Flexible Substrate," Antennas Wirel. Propag. Lett. IEEE, vol. 12, pp. 170-173, 2013.

[14] B. K. Tehrani, et al., "Inkjet Printing of Multilayer Millimeter-Wave Yagi-Uda Antennas on Flexible Substrates," vol. 15, pp. 143-146, 2016.

[15] X. Huang, et al., "Binder-free highly conductive graphene laminate for low cost printed radio frequency applications," Appl. Phys. Lett., vol. 106, pp. 203105, 2015.

[16] T. Leng, et al., "Graphene Nanoflakes Printed Flexible Meandered-Line Dipole Antenna on Paper Substrate for Low-Cost RFID and Sensing Applications," IEEE Antennas Wirel. Propag. Lett., vol. 15, pp. 1565-1568, 2016.

[17] X. Huang, et al., "Highly Flexible and Conductive Printed Graphene for Wireless Wearable Communications Applications," Nat. Publ. Gr., pp. 1-8, Nov 2015.

[18] A. Lamminen, et al., "Graphene-Flakes Printed Wideband Elliptical Dipole Antenna for Low Cost Wireless Communications Applications," 2018.

[19] J. Suikkola, et al., "Screen-Printing Fabrication and Characterization of Stretchable Electronics," Sci. Rep., vol. 6, pp. 1-8, 2016.

[20] K. Arapov, et al., "Graphene screen-printed radio-frequency identification devices on flexible substrates," Phys. Status Solidi - Rapid Res. Lett., vol. 10, pp. 812-818, 2016.

[21] M. Akbari, et al., "Fabrication and Characterization of Graphene Antenna for Low-Cost and Environmentally Friendly RFID tags," IEEE Antennas Wirel. Propag. Lett., vol. 1, pp. 1-1, 2015.

[22] X. Cao, et al., "Screen printing as a scalable and low-cost approach for rigid and flexible thin-film transistors using separated carbon nanotubes," ACS Nano, vol. 8, pp. 12769-12776, 2014.

[23] W. J. Hyun, et al., "High-resolution patterning of graphene by screen printing with a silicon stencil for highly flexible printed electronics," Adv. Mater., vol. 27, pp. 109-115, 2015.

[24] S. Ahmed, et al., "A Compact Kapton-Based Inkjet-Printed Multiband Antenna for Flexible Wireless Devices," IEEE Antennas Wirel. Propag. Lett., vol. 14, pp. 1802-1805, 2015.

[25] G. A. E. V. Soliman, et al., "Bow-tie slot antenna fed by CPW," Electron Lett, vol. 35, pp. 514-515, 1999.

[26] R. Simons, "Coplanar waveguide circuits, components, and systems," vol. 7, 2001.

[27] T. Ji, et al., "Ku-band antenna array feed distribution network with ferroelectric phase shifters on silicon," IEEE Trans. Microw. Theory Tech., vol. 54, pp. 1131-1138, 2006.

\section{BIOGRAPHIES OF AUTHORS}

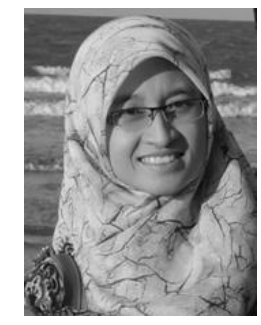

Siti Nor Hafizah Sa'don received Bachelor Degree of Electrical Engineering with Honour and Master of Electrical Engineering from Universiti Tun Hussein Onn Malaysia in 2011 and 2013, respectively. Both studies are majoring in communication. She joint the Wireless Communication Centre as Assistant Research Officer in 2013 and Research Officer in 2014. Now, she is pursuing PhD in Electrical Engineering with the Wireless Communication Centre, Universiti Teknologi Malaysia. Her research interests include fifth generation (5G) antenna, graphene antenna, analysis of tuneable antenna based on graphene properties including dielectric and morphology properties of graphene, array antenna, transparent antenna, and specific absorption rate (SAR). 

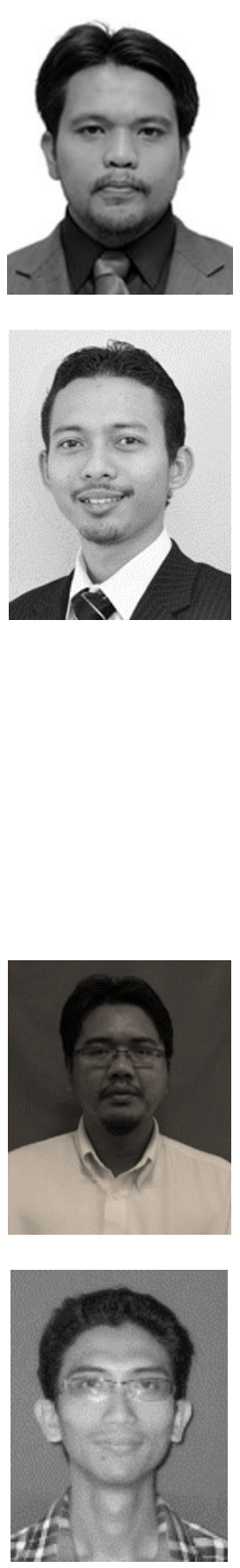

Mohd Haizal Jamaluddin received bachelor's and master's degrees in electrical engineering from Universiti Teknologi Malaysia, Malaysia, in 2003 and 2006, respectively, and the Ph.D. degree in signal processing and telecommunications from the Université de Rennes 1, France, in 2009, with a focus on microwave communication systems and specially antennas such as dielectric resonator and reflectarray and dielectric dome antennas. He is currently an Associate Professor with the Wireless Communication Centre, Faculty of Electrical Engineering, Universiti Teknologi Malaysia. His research interests include dielectric resonator antennas, printed microstrip antennas, MIMO antennas and DRA reflectarray antennas. He has published more than 25 papers in reputed indexed journals and conference proceedings.

Muhammad Ramlee Kamarudin obtained his first degree from Universiti Teknologi Malaysia (UTM), Johor Bahru, Malaysia, with honors, majoring in electrical and telecommunication engineering and graduating in 2003. He received the M.S. degree in communication engineering in 2004 from the University of Birmingham, Birmingham, UK, and later he obtained his Ph.D. degree in 2007 from the same University under the supervision of Professor Peter Hall. Dr Kamarudin is currently working as a Senior Lecturer at Centre for Electronic Warfare, Information and Cyber (EWIC), Cranfield Defence and Security, Cranfield University, UK. He is an author of a book chapter of a book entitled Antennas and Propagation for Body-Centric Wireless Communications and has published more than 200 technical papers in journals and proceedings including IEEE Transaction on Antenna and Propagation (TAP), IEEE Antennas and Wireless Propagation Letter (AWPL), IEEE Antenna Magazine, IEEE Access, International Journal of Antennas and Propagation (IJAP), Progress in Electromagnetics Research (PIER), Microwave and Optical Technology Letters (MOTL), and Electronics Letters. His research interests include antenna design for $5 \mathrm{G}$, wireless on-body communications, in-body communications (implantable antenna), RF and microwave communication systems, and antenna diversity. Moreover, Dr Kamarudin is an IEEE Senior Member (SMIEEE), a Member of IET (MIET), an Executive Member of Antenna and Propagation (AP/MTT/EMC), Malaysia Chapter, and a Member of IEEE Antennas and Propagation Society, IEEE Communication Society, IEEE Microwave Theory and Techniques Society and IEEE Electromagnetic Compatibility Society.

Fauzan Ahmad received the bachelor's in Mechatronics from Universiti Teknologi Malaysia in 1999, Master's Degree (Image processing) and PhD Degree in Electrical Engineering (Photonics) from University of Malaya in 2007 and 2014, respectively. He is currently a senior lecturer at Department of Electronic Systems Engineering, Malaysia-Japan International Institute of Technology (MJIIT), Universiti Teknologi Malaysia. He is a member of Optical System and Devices (ODESYS) Ikohza of MJIIT and his research interest includes nano material based for optical pulse laser generation, optical fiber sensor and microwave applications.

Samsul Haimi Dahlan received the Degree in Electrical Engineering from the Universiti Kebangsaan Malaysia in 1999, Masters Degree in Electrical and Electronic Engineering from the Universiti Teknologi Malaysia in 2005, and the Ph.D Degree in Signal Processing and Telecommunications from the Universite de Rennes I, France in 2012. He is currently an Associate Professor with the Faculty of Electrical and Electronic Engineering, Universiti Tun Hussein Onn Malaysia, and holds the position as the head of Research Center for Applied Electromagnetic (EMCENTER) since 2015. He is one of the ALUMNI for the Leaders in Innovation Fellowship programme with the Royal Academy of Engineering, UK and holds several intellectual property rights on several innovative products. He has authored and coauthored more than 30 ISI/Scopus journals and over 30 conference papers. His research interests include Optical-Microwave generator, focusing system (dielectric lens and transmit array's synthesis), advance antenna design, material characterization techniques, and Computational Electromagnetic. He is currently supervising a number of bachelor's, master's and Ph.D students and involved in several research projects sponsored by the industry and government agencies. 